\title{
NOTAS SOBRE LA RELACIÓN \\ ENTRE SISTEMA DE CARGOS OTOMÍ Y ESTADO
}

\author{
Notes ON THE Relation \\ between Otomí Cargo System and State
}

\section{Jorge Uzeta Iturbide*}

Resumen: En este texto se explora el papel de los cargos o mayordomías otomíes en tanto formas pedagógicas de gobierno y prácticas de autonomía, así como su creciente cercanía a los principios multiculturales que impulsa el Estado mexicano. Estos últimos incluyen la mercantilización de la diferencia cultural y en una línea semejante el financiamiento o apoyo a los desempeños locales "tradicionales", en este caso las propias mayordomías. Aceptar o no financiamiento sobre prácticas de autonomía supone no sólo la redefinición de las competencias del Estado sino también, para los propios implicados, un dilema sobre la naturaleza misma de sus organizaciones y quehaceres rituales.

Palabras clave: mayordomías, gobierno, autonomía, élites, partidos políticos.

Abstract: This article explores the role of traditional otomí cargos or mayordomías as pedagogic forms of government and autonomic practices, as well as its growing closeness to the multicultural prin-

* Doctor en Ciencias Sociales. Centro de Estudios Antropológicos de El Colegio de Michoacán, México. Trabaja temas relacionados con etnicidad, memoria y multiculturalidad, http://orcid. org/0000-0003-0065-5923, correo e.: jorgeuzeta@colmich.edu.mx Fecha de recepción: 0103 18; Fecha de aceptación: 260618.

(cc) EY-NC-ND Páginas 143-162. 
ciples put forward by the Mexican state. These include the mercantilization of cultural difference and, along this line, the funding and sponsoring of the "traditional" local practice, in this case, the mayordomías. Accepting or rejecting financial support for autonomic performances means not only the redefinition of the State field but also, for those involved, a dilemma over the nature of their organization and ritual practices.

Keywords: mayordomías, government, autonomy, elite, political party.

\section{Los apoyos y las mayordomías}

Varios fragmentos de una charla con el entonces tesorero del municipio guanajuatense de Tierra Blanca parecen reveladores a propósito de la relación entre cargos religiosos tradicionales e instituciones estatales. Este vínculo ha comenzado a ser reconstruido a partir del posicionamiento multicultural del Estado mexicano. El funcionario referido no es, en ese sentido, uno cualquiera: además de haber cursado estudios universitarios y de ejercer sus labores en el ayuntamiento, se desempeñaba al momento como segundo mayordomo de la santa Cruz, símbolo muy venerado entre la población otomí colindante a Tierra Blanca. De hecho se trata de un miembro destacado de la élite política de la Congregación de San Ildefonso de Cieneguilla, ubicada en aquel municipio a pocos kilómetros de su cabecera. Esta persona me decía lo siguiente:

Ha faltado gestión para las mayordomías [de la Congregación]. Los recursos [obtenidos] son para cuestiones básicas. Ha llegado recursos [institucionales] para danzas, pastorelas, alabanceros, comida típica... Las mayordomías no reciben, no lo han pedido. Sería bueno que lo hicieran, pero ha faltado información y recursos para gastos ...

Más adelante, al calor de la charla se mostró menos confiado en esa última idea: 
Siento temor de que entren recursos, siento que el objetivo se desvirtuaría. Una cosa es una ayuda, pero otra que el gobierno dé. Si yo soy mayordomo y si sé que hay recursos [decía trazando un supuesto] yo voy a querer que me den... hay que ser más independientes en eso. Ahí somos escépticos de meternos a un programa. ... Hay instituciones que quieren entrar. [La mayordomía] es una buena estructura, con apoyo [de la gente]. Si es una lucha por el dinero se pierde la esencia, se puede dar que llegue la gente que vea a la ley [indígena guanajuatense, aprobada en 2011] para [obtener] recursos, ¿por qué no piden recursos? Hay mayordomos que quieren ver eso, que hay que pedir. Ya hay gente que se los ha dicho (entrevista a Salvador Hernández, Tierra Blanca, Guanajuato, 8 de mayo de 2014).

Hasta ese momento el carácter de la organización y las prácticas rituales en la Congregación se habían mantenido al margen de intervenciones institucionales, incluidas las de la Iglesia católica, cuya participación ha sido históricamente intermitente y en todo caso subordinada, pero también las de los partidos políticos, a los que este mayordomo aludió vagamente en la misma plática y sobre el mismo tema. Se trataba entonces, como ahora, de un asunto de la mayor relevancia porque se tenía la idea de que — lo cito de nuevo añadiendo énfasis_ " "las mayordomías son las que manifiestan vivamente lo indígena, es la esencia, está viva la cuestión principal de los pueblos indígenas. Si no, desapareceríamos como pueblos indígenas. Ésas son las actividades que nos identifican”.

Justo por eso, y bajo la idea de conservar y estimular las tradiciones culturales, algunas mayordomías comunitarias solicitaron y recibieron apoyo económico directo del municipio desde 2016 (Ortiz, 2017: $\mathrm{s} / \mathrm{p}$ ), lo que no sólo quebranta el principio de laicidad aún en boga, establecido en su momento por el Estado mexicano postrevolucionario, sino que supone un avance serio de las instituciones estatales sobre los desempeños religiosos centrales de la Congregación, que comparten todas las comunidades a las que me referiré en adelante. Así pues, para analizar la distancia y la relación entre cargos y la formación actual del Estado mexicano — neoliberal de acuerdo con su perfil económico 
anti proteccionista - debemos contextualizar la perspectiva anterior, su razón de ser y sus efectos políticos. Entre otras cosas debemos tener presente que la Congregación está integrada por diecinueve comunidades, cada cual con su propia mayordomía y ritualidad, enlazadas entre sí a partir de la veneración conjunta a siete "santitos". Cada mayordomía está confiada al cuidado de cuatro parejas de cargueros y cada una de éstas auxiliada a su vez por otras cuatro parejas entre ayudantes — maleteros - y cocineras — guzneras.

Los 56 cargueros y aproximadamente 224 ayudantes de esas siete mayordomías se desempeñan conjuntamente para acciones principales en cada festejo, o diferencialmente para numerosos quehaceres colaterales. Estos últimos están bien ejemplificadas por las procesiones, recepciones de imágenes, "pedimentos" y solicitudes de apoyo; sin considerar los desempeños de las mayordomías de cada comunidad, hablamos de aproximadamente un centenar de todas estas acciones rituales a lo largo del año. Cada una de ellas está marcada por constantes y múltiples intercambios de bienes en una lógica de prestaciones y reciprocidad bien conocida y muy estudiada por la antropología a partir de Mauss (1979): dar para recibir y volver a dar. No es, desde luego, un principio exclusivo de las mayordomías, sin embargo muchos bienes destinados al consumo se movilizan de esta forma.

Aunque abiertos a lo contingente, esos desempeños tienen una gramática particular evidenciada en la ubicación de cada carguero cuando las mayordomías se ponen en formación, así como en sus ámbitos de responsabilidad y jerarquía. La incesante repetición de acciones y las disposiciones físicas o espaciales de sus miembros remarcan, entre muchas otras cosas, a) la relación entre mujeres y ámbitos domésticos; b) la asociación entre el primer mayordomo y la cabeza de un cuerpo, y la de los restantes cargueros con los brazos del mismo; c) el vínculo entre el larguero de la cruz, atravesado por la vertical, y la posición separada de mujeres y hombres ante el símbolo. Finalmente, d) subraya una y otra vez principios patriarcales a partir de la primacía de los padres sobre los hijos y del hombre sobre la mujer.

Los cargos expresan principios deseables de organización social que son reiterados pública y constantemente. Además, en el despliegue ritual 
de esos principios el quehacer de los mayordomos va construyendo sentidos de continuidad histórica y espacial que la Congregación ha utilizado en diferentes momentos para demandar atención estatal lo mismo que para defender su territorio (Piña, 2002; Uzeta, 2004: 149). En paralelo, los cargos son recursos para la estructuración de ámbitos de interacción ordenada o normada entre vecinos.

No obstante, aquellas actualizaciones de organización y preeminencia patriarcal van en sentido contrario a los cambios ya asumidos en la vida cotidiana, bien representados por la creciente movilidad femenina y su inserción en diferentes mercados laborales remunerados - el agrícola industrial, el comercial, el de servicios, etc.- - La capacidad de decisión de las hijas en términos económicos y matrimoniales, la migración cada vez menos negociada de los hijos, e incluso la mayor diferenciación socioeconómica y política al interior de las comunidades, también contradice la gramática ritual.

Debemos preguntarnos sobre la persistencia de aquellas representaciones prescriptivas de jerarquía, orden e intercambio, en un contexto en el que la propia dinámica social parece rebasarlas. Esta supuesta paradoja, sugiero, trasciende la construcción política de narrativas de continuidad espacial y temporal para relacionarse con el hecho de que los cargos y sus desempeños han constituido una versión discreta y local de espacio público (Habermas, 1991), misma que podría comprenderse como un ámbito autónomo de organización.

La anterior no es una idea nueva, desde luego, pero es relevante porque nos dirige no sólo a la asociación entre cargos y espacio por un lado, con los intercambios de apoyos y de información por el otro, sino que también nos lleva a la identificación de una pedagogía de gobierno, pues los cargos son ámbitos para generar y ejercer prácticas de servicio y atención, de organización, discernimiento y toma de decisiones a través de autoridades dispuestas por jerarquía. En este sentido se aprende y se educa en colectivo lo respectivo al mantenimiento del orden social. Algo de esto ha sido esbozado de manera a veces directa, otras oblicua, por autores que se han ocupado de las mayordomías y los sistemas normativos (Aguirre Beltrán, 1981 [1953]; en el otro extremo Barabas, 2013, etc.). En esta línea lo que interesa de manera particular es que aquella 
vertiente de autonomía organizativa puede estar en riesgo a partir precisamente de la incursión y financiamiento institucional a los cargos y a sus desempeños bajo el argumento multicultural de su protección.

\section{Sobre el sistema de cargos}

Los sistemas de cargos han atraído poderosamente la atención por su flexibilidad y sus múltiples implicaciones sociales a partir de la discusión clásica sobre las relaciones entre economía, demografía y política en ámbitos étnicos (Hewitt, 1988: 95-108). Ampliando o tratando de desmarcarse de ese debate se han abordado los efectos de ese sistema con respecto a un mundo de cosas: a la adaptación ecológica, a la producción y los mercados; a su papel en el desarrollo y legitimación de poderes locales asociados también con formas de prestigio, identidad diferencial y como escuela de liderazgos; como elemento vinculado a una rearticulación política de corte étnico bajo el dominio colonial o, en el extremo opuesto, como parte de "usos y costumbres" que hoy son formas postcoloniales de dominación; como elemento de mediación entre principios de reciprocidad y clases sociales; y entre mucho más, como expresión de la cosmovisión y mecanismo de prestaciones y contraprestaciones simbólicas entre lo humano y lo divino (Dow, 1990 [1974]; Galinier, 1990; Carmagnani, 1993; Jacinto, 1995; Rodríguez, 1995; Bartra, 1999; Padilla, 2000; Ortega y Mora, 2014, etc.).

También resultan relevantes las referencias hechas a su supuesta naturaleza mesoamericana, comunal y agraria, así como a su propensión autonómica, lo que ha permitido señalar sus posibles implicaciones con expresiones normativas y jurídicas (Aguirre Beltrán, 1981 [1953]; Medina, 1995; Korsbaek 1996; Siverts, en Korsbaek 1996: 279). Quizá por eso mismo en distintas partes del país sectores tradicionalistas han podido argumentar que rituales y cargos son prácticas irreductibles o "esencias" locales, alimentando de esta manera resistencias y conflictividades intracomunitarias ante la creciente diversidad religiosa (véase Rivera et al., 2005).

Pese a la pertinencia de estos enfoques, algunos excelentes estudios regionales que abordan la relación entre localidades y formaciones estatales han sugerido que, en tanto estructura comunitaria, el sistema de 
cargos cambia de sentido y alcance dependiendo del momento histórico y de la articulación de lo local con los poderes políticos y económicos que están más allá de él. Como Ochiai (1985), Wasserstrom (1992 [1983]), y Rus (2002 [1995]) indican, eso suele implicar también una restructuración de las relaciones internas.

En complemento, y pensando específicamente en la Congregación otomí, es pertinente llamar la atención sobre el papel del sistema de cargos como una expresión de gobierno, es decir, como un "sistema de reglas para mantener el orden social" (Simons, 2000: 265) en tanto que conllevan, reitero, la construcción de un espacio de acceso abierto y, a través de él, la práctica y la comunicación pública de preceptos normativos y referentes ideales para la convivencia: una pedagogía. Ahí se producen y afianzan jerarquías políticas internas y entre muchas cosas más se dispone de la circulación y la redistribución de recursos de distinta índole bajo el principio de reciprocidad, mismo que no es ajeno a la economía de mercado.

Aquí el énfasis está en la expresión pública de una serie de principios destinados a la actualización de la interacción social, organizada bajo términos sacros por asociación con los símbolos que las mayordomías resguardan, lo que fortalece su sentido normativo de autoridad. Es decir, propongo seguir la dimensión formativa y pedagógica del sistema ritual otomí como una práctica de reglamentación, más sugerida que obligatoria, por sobre su posible orientación restrictiva en términos jurídicos, de poder, o de control y vigilancia. Aunque no me ocuparé de esto, su influencia se extiende hacia la renovación, sujeta a las adecuaciones del momento, de las nociones de membresía, de comunidad y de identidad diferencial que son desplegadas de distinta manera ante instituciones estatales, civiles y eclesiales.

Si el espacio público es articulado para que la organización de cargueros transmita libremente valores modélicos es porque se trata de un espacio abierto aunque jerarquizado, y en ese sentido con visos de compartimentalización. Por ejemplo, las cocinas en donde se preparan y sirven alimentos en el contexto festivo es un ámbito principalmente femenino en el que los hombres se subordinan a los dictados de las guzneras, proveyendo constantemente de agua y madera para el fogón. 
Cualquiera puede fisgonear por ahí, pero difícilmente puede intervenir. Otro ejemplo son las mayordomías cuando van con todos sus atributos a cuestas. Ahí se marcan posiciones diferenciales y fronteras que no se transgreden: mientras ellas discuten alguna cosa específica esperando la decisión del carguero que las encabeza - por decir, el horario e itinerario del día siguiente- la gente se mantiene en sus lugares, flanqueándolas, para después, en el transcurso de la acción ritual, enterarse qué dijo quién y cómo, y opinar en consecuencia.

Este ejercicio compartido de comunicación, que además de la transmisión de principios incluye comentarios, opiniones e incluso bromas e ironías, es el que dota de sentido al espacio público como tal, pues ahí se dilucidan posibilidades y nexos sociales (Escalante, 1995: 42). Se trata de un ámbito pedagógico y normativo de manera que el acceso franco a valores y a formas de organización común estaría perfilado para generar posicionamientos compartidos. Los rituales y los cargos lo hacen de una manera más amplia, más clara y más constante que, digamos, la competencia electoral y las asambleas comunitarias, éstas por sus propias transformaciones suelen tener mayores restricciones en términos de acceso por origen, sexo y edad.

En otro contexto, y abonando a su sentido normativo, los cargos religiosos y los festejos rituales en los que se involucran han sido ámbitos que históricamente quedaron fuera de la intervención institucional, probablemente porque estuvieron al margen del proceso de formación del Estado postrevolucionario. Dados los principios seculares que animaron a este último, y que quedaron tan bien subrayados en la teoría y en la acción indigenista, las autoridades federales y específicamente las guanajuatenses reconocieron preferentemente como puntos de enlace y mediación local a autoridades civiles en el marco del municipio o del ejido, siendo el caso. El hecho es que el actual rediseño multiculturalista y neoliberal del Estado está planteando la redefinición de aquellos límites (Das y Poole, 2004), que coinciden con el engrosamiento de una élite otomí constituida por individuos de perfiles laborales y profesionales muy diversos. 


\section{Espacios de autonomía e interacción}

Es necesario entonces puntualizar algo sobre élites, readecuación de límites estatales y cargos a través de lo referente a cuatro temas: 1 . representación política, 2. regulación de animadversiones, 3. apoyos económicos, y 4. comercialización de la diferencia.

1. En la Congregación no hay un entrelazamiento formal entre responsabilidades rituales y las de representación comunitaria. No se trata de un sistema de escalera que intercala desempeños religiosos y civiles hasta que la pareja llega a una posición emérita en el Consejo de Ancianos. Es posible que eso no haya existido en el lugar pese a que las mayordomías puedan argumentarse como derivaciones de las cofradías coloniales. En realidad la autoridad política tiene que ver con la propiedad de la tierra, no sólo con el territorio y la cosmovisión; en efecto, en la Congregación la representación política se definió en el último tercio del siglo XIX mediante el procedimiento poco común de la compra de tierra a una hacienda cercana, lo que eventualmente influyó en la comprensión local de las parcelas como bienes mercantilizables, si bien bajo ciertas restricciones (Uzeta, 2010: 103; Urbina, 2016).

Aunque no hay un entrelazamiento formal entre responsabilidades rituales y las de representación comunitaria y municipal, ha sido común que quienes desempeñan estas últimas ejerzan antes o después como cargueros o como ayudantes de los mismos. No sólo el actual alcalde (julio 2018), triunfante con el Partido Revolucionario Institucional, PRI, ha estado implicado en los cargos, sino que su antecesor panista — del Partido Acción Nacional, PAN_- ha sido mayordomo un par de veces — volveremos más adelante con este último-, lo mismo que varios de los presidentes municipales que le precedieron y que en su momento lograron el puesto por el Partido de la Revolución Democrática, PRD, o por PRI. Entre ellos se cuenta el tesorero municipal al que me he referido en las páginas iniciales.

Esta orientación informal de entrelazamiento entre lo ritual y lo electoral contribuyó a la definición del pequeño grupo que, junto a la figura de "representante general", directamente relacionada con la compra de tierras ya mencionada, dio forma a la delegación municipal 
de la Congregación, también con un carácter bastante autónomo. En un municipio controlado por familias mestizas de la cabecera hasta la década de 1990 — salvo por un par de trienios_- la delegación política se convirtió en el espacio en el que las comunidades se posicionaban con respecto a las autoridades civiles e incluso a las eclesiales, asentadas en la parroquia de la cabecera terrablanquense.

Aquel pequeño grupo de representantes estaba formado por trabajadores rurales de distinto tipo — jornaleros, aparceros - que podrían haber sido caracterizados en sentido amplio como campesinos. Sin embargo, a partir de la introducción de escuelas en la Congregación, del surgimiento local de un grupo de maestros que se desempeñan laboralmente en ellas, de la creciente importancia económica de la migración laboral, y de la posibilidad real de competir por el control político del ayuntamiento - inicialmente dentro del PRI y posteriormente a través de diversos partidos políticos_-, el perfil y los intereses de estos representantes comenzaron a diversificarse.

Como efecto de lo anterior, y dados los permanentes conflictos con los vecinos mestizos, la representación política a nivel de las comunidades y la Congregación pasaron de ser una responsabilidad poco deseable a un entrenamiento con vista a la posterior incursión en la vida electoral del municipio. El asunto también se vio estimulado por los beneficios económicos que aquellos puestos ganaron a partir de la reforma municipal impulsada por la Federación en la década de 1980. Así, incluso generacionalmente se ha ido renovando y consolidando un estrato político interesado en la competencia electoral y al mismo tiempo en fortalecer el argumento de la distintividad cultural otomí, involucrándose en las mayordomías y en el crecimiento de sus festividades. Un claro contraste con la aspiración integracionista y unificadora del indigenismo de la postrevolución.

Actualmente, y partiendo de los maestros locales, esa élite se ha ampliado gracias a pequeńos comerciantes, profesionistas y productores agrícolas proempresariales. Todos ellos pugnaron por una ley indígena para la entidad desde inicios del presente siglo, y afianzan públicamente su posición y sus intereses personales y de grupo a través de su desempeño como cargueros. Es decir, al subordinarse a valores y 
principios de organización, compartidos y manifestados en términos de una pedagogía de gobierno en el ámbito ritual otomí, básicamente autonómico, se legitiman como agentes políticos.

Aquí regreso al edil del periodo 2012-2015 porque su caso es ilustrativo al respecto. Resulta trascendente, además, por su parentesco con un ex alcalde que a inicios de los años noventa maniobró exitosamente en beneficio de la Congregación para despojar de un prometedor proyecto educativo a los vecinos de la cabecera. De mediana edad, este hombre ha tenido experiencia migratoria internacional desde sus 28 años, el desempeño que tuvo como jornalero agrícola en Estados Unidos le permitió la solvencia económica para desempeñar, junto con su esposa y "cuando éramos jóvenes", dice, cargos rituales de importancia. El primero y de mayor peso fue el encabezar la mayordomía de la santa Cruz; pocos años más tarde fungió como carguero del Sagrado Corazón de Jesús.

Su discurso político, que incluye términos como el "orgullo por las raíces" y una fe en el "progreso", se potenció en su periodo con esfuerzos para la conservación y difusión de las "tradiciones" y con la recuperación y réplica de experiencias "exitosas" en comunidades otomíes. Con eso refería a la rehabilitación de capillas familiares coloniales y a su impulso combinado con la gestoría de proyectos ecologistas. Aún antes de la ley indígena, el financiamiento de estos últimos provenía tanto de la Comisión Nacional para el Desarrollo de los Pueblos Indígenas, CDI, como de asociaciones civiles ligadas a empresas transnacionales.

Gracias a su posición y trabajo, este hombre ha logrado que sus cinco hijos cursen estudios de licenciatura en la Universidad Michoacana, profesionalización que es una de las características más destacables de las nuevas élites otomíes.

2. La legitimación del desempeño político a través del sistema de cargos y del ámbito ritual sucede independientemente de las adscripciones o simpatías partidistas de los cargueros y prácticamente de todos los vecinos, que suelen reorientarse en cada elección de alcalde a partir de lógicas de patronazgo e intercambio. La promesa de apoyos y dádivas se traducen en proselitismo y votos muy a tono con el principio local 
de reciprocidad; así se rentabilizan políticamente las desigualdades y jerarquías. No es raro que los recursos económicos, proyectos y ayudas se multipliquen en esos momentos tanto desde las instancias del gobierno de la entidad como a través de los partidos políticos, y que todo ello promueva el volátil reposicionamiento de lealtades electorales.

No obstante, dadas las tensiones internas que las elecciones provocan, los propios vecinos han identificado una relación entre votaciones y los cargos religiosos que tienen que ver con las ya señaladas orientaciones y pedagogía para el mantenimiento del orden. Es decir, con la convivencia cotidiana pese a la lucha partidista:

Las mayordomías activan la relación pública de personas que están enfrentadas por cuestiones políticas. Si se sientan a la mesa con los otros... se suavizan las relaciones a través de la convivencia. Se vuelven a sentar las partes de manera "natural" y [todo] se equilibra. Y con las comunidades se llega mejor. Yo lo he vivido de que "siéntese aquí"; “iah!, ipero están esos con los que me enfrenté!, bueno ... ni modo de decir que no, que no me siento ahí...”. Uno se tranquiliza, convive con gente que no se pensaba, y [el asunto] se ve diferente. Es la fe, las mayordomías y la voluntad de todos (entrevista, Tierra Blanca, Guanajuato, 8 de mayo de 2014).

Aunque efectivamente el ámbito ritual disuade de rupturas de fondo, cosa que estaría implícita en los valores y en las nociones de gobierno transmitidos y enseñados a través de cargos y rituales, etnográficamente se puede constatar que también es un lugar para expresar controladamente animadversiones de distinto orden, entre ellas las vecinales, las familiares y las electorales y de clase. Además —y esto resulta importante- es un espacio que se utiliza para trazar relaciones políticas que trascienden las coyunturas de sufragio, como lo veremos más adelante.

3. En Guanajuato los apoyos federales a las comunidades congregadas anteceden con mucho a la promulgación en 2011 de la ley indígena. Esos recursos se habían enfocado básicamente a cuestiones de infraestructura y salud, y en menor medida, aunque de manera constante, a 
algunas manifestaciones artesanales tenidas como tradicionales. Con el sesgo multiculturalista adoptado en la Constitución política federal y suscrito por el gobierno de la entidad, ese tipo de promociones se ha ido ampliando hacia diversas expresiones culturales, si bien con la idea intrínseca de que se agotan en lo recreativo, y que son o deben ser inocuas en términos de defensa y demanda política. Así lo sugieren los numerosos concursos y premiaciones impulsados por el Instituto de Cultura de la entidad en torno a la "cocina tradicional indígena", a la recopilación de cuentos y leyendas, a la confección de cestería, a los artesanos populares, etcétera.

En un nivel de mayor incursión en el ámbito ritual, y en concordancia con el discurso multicultural en boga, tanto CDI, el municipio y la dependencia de cultura referida, han canalizado recursos en apoyo a grupos que se mueven en torno de los cargueros y sus festejos, como los alabanceros, los danzantes y los músicos tunditos. Han auxiliado también con agua potable y transporte para gente mayor cuando acontece la larga peregrinación hacia el Pinal del Zamorano en mayo, cerro con fuertes connotaciones territoriales y sacras dentro de todo el sistema ritual otomí; incluso financiaron el remozamiento de espacios involucrados en el ritual, como ocurrió con las "cocinas", locación fundamental en el que las mayordomas y sus guzneras preparan las grandes comidas públicas que se realizan en momentos culminantes de los festejos.

Esas inversiones en la recreación de lo distintivo otomí, a las que se agregan recursos para el diseño y confección de ajuares "tradicionales" que los ancianos y niños lucen en ocasiones especiales, han perfilado a las celebraciones como escenarios para la recepción de invitados especiales (Escalona, 1998). Como tales han pasado por ahí jerarcas religiosos y gente de asociaciones civiles, pero sobre todo políticos en funciones con quienes las élites locales buscan entendimientos, intercambios y compromisos de diverso orden.

Un ejemplo elocuente de lo anterior ocurrió hace ya varios ańos, en 2009, en el festejo del aniversario 473 de la fundación de Cañada de Juanica, una de las comunidades congregadas. Los organizadores hicieron coincidir los homenajes a un par de hijos ilustres del lugar - uno maestro, otro sacerdote- con la inauguración de un jardín 
comunitario y de un mural que celebraba a sus antepasados. De manera más destacada, lo emparejaron con el recibimiento de las mayordomías. El festejo fue preparado por una organización que pese a su nombre es de cuño reciente, el Consejo de Ancianos de Juanica. Para ello, dispusieron de espacios y de actividades de tal manera que inhabilitaron el carácter de espectadores de sus invitados, haciéndolos participantes y validadores del sentido del evento. Entre los convidados hubo una nutrida presencia de funcionarios del Instituto Estatal de la Cultura de Guanajuato, de la Coordinadora regional de CDI, del Centro de las Artes de la entidad, funcionarios entrantes y salientes del ayuntamiento de Tierra Blanca, y diversos representantes de asociaciones civiles. En su momento algunos de ellos tomaron el micrófono para destacar el esfuerzo local y valorar los aportes de los homenajeados así como los compromisos comunales.

Lo notable de ese tipo de convivencias es que de manera manifiesta se generan espacios de interacción en los que se muestran abiertamente proyectos culturales locales — religiosos y políticos a la vez-y se (re) crean o reajustan públicamente vínculos de interés y de clientela con agentes externos, además de otros tantos de diversa índole, entre ellos los familiares y vecinales.

4. El enfoque anterior del ámbito ritual como un punto de cruce entre la organización directiva, la cosmovisión, el folclore inocuo y el utilitarismo político, es aceptado por un buen número de miembros de las comunidades que desde hace tiempo acarician la idea de hacer concurrir a las celebraciones a los santos con un más amplio y redituable evento comercial. El referente directo es la cabecera municipal, que ha logrado combinar su festejo patronal a santo Tomás con la conmemoración de la fundación del lugar, dando como resultado una feria artística y de mercado traslapada a las actividades religiosas.

En un sentido semejante hay un proyecto que podría medir la rentabilidad económica de la ritualidad otomí, y que se inscribe en el impulso al turismo ecológico y de aventura. Al par de ofertas que ya existen en la Congregación, con caminatas por jardines de cactáceas, se intenta sumar el pequeño venero del centro de Cieneguilla. Si bien se trata de 
un espacio público, la pequeña alberca adyacente que se alimenta de esas aguas fue construida hace muchos años específicamente para el goce gratuito de los vecinos de las comunidades. La idea de perfilarla como balneario con apoyo de la institución de fomento turístico de la entidad siempre fue motivo de disputas en el supuesto de que únicamente Cieneguilla, asiento del venero, se beneficiaría económicamente de un recurso que formalmente pertenece a toda la Congregación.

Las cosas parecen estar cambiando, como sugiere información recurrente publicada en medios estatales. Una de esas notas reproduce las palabras del delegado de aquella comunidad: "Sería un buen proyecto [el de reestructurar el balneario para el turismo] ... nosotros queremos externar nuestra cultura y atractivos para que la gente viva nuestra cultura”. En ese tono, que es el del multiculturalismo oficial, también se habla de resistencia cultural asociando este tipo de proyectos con el impulso a su identidad (Rubio, 2014: s/p).

Lo que subyace a esta aspiración turística es el hecho de que en la cosmovisión otomí ese afluente está ligado con la capilla central de la Congregación, donde tienen su sede dos imágenes patronales confiadas a los cargueros, san Ildefonso y la virgen de Guadalupe. El papel de este venero, a tiro de piedra del templo, tiene connotaciones amplias al estar vinculado con referentes territoriales que incluyen un par de cerros con atribuciones acuícolas y de género, uno de ellos ya referido, y que también están ligados con las imágenes encomendadas a los cargueros, en particular con la santa Cruz. Así, un espacio público con atribuciones territoriales sacras bien puede ser incorporado a un proyecto económico de perfil recreativo en donde tendrían injerencia las instituciones municipales y estatales.

\section{Encrucijada}

He intentado esbozar de manera heterodoxa aunque estimulante, espero, algunos puntos de relación actual entre cargos religiosos otomíes e instituciones de estado. Si estas últimas ignoraron durante la postrevolución el ámbito religioso otomí en su intención de generar una entidad nacional culturalmente unificada, impulsando para ello el surgimiento de intermediarios civiles, el actual rediseño del sistema 
político no sólo reconoce las diferencias sino que las alienta en términos mercantilistas, folclorizados.

Los quehaceres religiosos referidos testimonian, por su parte, la articulación de espacios públicos en los que se realiza una pedagogía de gobierno: se comunican principios normativos y de autonomía que paradójicamente no son ajenos a la consolidación de élites políticas, actualmente diversificadas en lo económico y en lo electoral. Quizá sea el perfil de gobierno que les es propio lo que ahora las hace políticamente rentables y dignas de intervención institucional. En ese sentido el reconocimiento estatal de la diferencia, y sus expresiones de apoyo a las prácticas y formas de organización y gobierno locales, están redefiniendo los límites de la acción institucional. Aquí se busca reajustar el trazo sobre los espacios religiosos propiamente otomíes que resultaron de circunstancias históricas ya esbozadas, entre ellas el secularismo municipalista de la postrevolución, el limitado y lento relevo de la entonces delgada capa política local, y las propias tendencias organizativas de las comunidades congregadas.

Así, la Congregación se encuentra ante una encrucijada de gran trasfondo histórico con respecto a su sistema de cargos y a sus rituales. Si estos devinieran económica e ideológicamente dependientes de instituciones estatales, en principio ajenas a las comunidades, es razonable preguntarse sobre su posible impacto en la transmisión de ideales sociales, normas de convivencia y nociones de organización y continuidad histórica.

En términos de los vínculos de intercambio y reciprocidad de bienes las aportaciones estatales podrían ir haciendo innecesarias las redes de apoyo de los cargueros. La lógica de reciprocidad ritual se orientaría entonces hacia fuera: de ser un principio interno podría llegar a ser un principio de relación con el Estado y de apoyo al mismo, en específico a los funcionarios que lo encabecen y representen al momento. Algo muy útil en contextos de partidos y competencia electoral.

A ese respecto, las instituciones estatales serían incorporadas a la lógica otomí pese a que esta última se vería seriamente modificada. Pero la anterior es una visión extrema, pues también es posible que el régimen de intercambios pueda sumar las aportaciones estatales sin alterar 
los apoyos internos, lo que daría como resultado una sobre abundancia de recursos. Los rituales podrían ganar en exuberancia con decoraciones y ajuares más recargados para los santos, y con el ofrecimiento pantagruélico de alimentos en las comidas públicas. No obstante, esto no despejaría la duda sobre el impacto político de esos apoyos — tampoco sobre la manera en que las aportaciones institucionales serían comprobadas para alejar cualquier sospecha de malos manejos.

De manera que la condición de los cargos y sus rituales como espacios normativos y pedagógicos podrían estimular las prácticas de las actuales y más numerosas élites otomíes, entre ellas su legitimación mediante el desempeño de responsabilidades religiosas. En consecuencia el ámbito ritual sería fortalecido como espacio para negociar públicamente la presencia del Estado y para rentabilizar prácticas y atractivos turísticos en concordancia con ciertas aspiraciones comerciales existentes en las comunidades.

En suma, el estímulo económico institucional puede trastocar el sentido político actual de las mayordomías a favor de intereses más acordes con la redefinición del Estado mexicano en su conjunto, beneficiando en esos términos a las capas ilustradas otomíes que ya se desempeñan por completo en el ámbito electoral. Esto mismo comprometería a los cargos como espacios de autonomía, de ordenamiento y regulación —o gobierno- específicamente propio. "El objetivo se desvirtuaría”, como me señaló con suspicacia el tesorero del municipio y mayordomo segundo de la santa Cruz.

Tal vez ése sea el camino para nuevas formas de representación otomí totalmente compatibles con el perfil del Estado neoliberal y multicultural, una imagen que sin duda resultará chocante para ciertos sectores locales por no hablar de muchos antropólogos. Sin embargo, la afinidad que esta posibilidad guarda con los intereses económicos de las comunidades otomíes, y con las aspiraciones políticas de élites con novedosos perfiles profesionales y proempresariales, también nos recuerda que los sistemas de cargos no tienen sentidos fijos e inmutables, sino históricos y en transformación. Aunque ahora el costo de ello pueda ser la cooptación de los ámbitos internos de gobierno. 


\section{Bibliografía citada}

Aguirre Beltrán, Gonzalo, 1981 [1953], Formas de Gobierno Indigena, INI, México.

Barabas, Alicia M., 2013, "El trabajo comunitario en las poblaciones indígenas actuales", en Arqueología Mexicana, noviembrediciembre, Año XXI, núm. 124, pp. 71-77.

Bartra, Roger, 1999, La sangre y la tinta. Ensayos sobre la condición postmexicana, Océano, México.

Carmagnani, Marcelo, 1993, El regreso de los dioses. El proceso de reconstitución de la identidad étnica en Oaxaca, s. XVII y XVIII, FCE, México.

Das, Vena y Deborah Poole (editors), 2004, Anthropology in the Margins of the State, School of American Research Press, James Currey Ltd., Santa Fe.

Dow, James W., 1990 [1974], Santos y supervivencias, INI, CNCA, México.

Escalante Gonzalbo, Fernando, 1995, Ciudadanos Imaginarios. Memorial de los afanes y desventajas de la virtud y apología del vicio triunfante en la República mexicana. Tratado de moral pública, El Colegio de México, México.

Escalona, José Luis, 1998, Etúcuaro: la reconstrucción de la comunidad. Campo social, producción cultural y Estado, El Colegio de Michoacán, México.

Galinier, Jacques, 1990, La mitad del mundo. Cuerpo y cosmos en los rituales otomies, UNAM, CEMYC, INI, México.

Habermas, Jürgen, 1991, The Structural Transformation of the Public Sphere. An Inquiry into a Category of Bourgeois Society, translated by Thomas Burger with the assistance of Frederick Lawrence, The MIT Press, Cambridge, Massachusetts.

Hewitt de Alcántara, Cynthia, 1988, Imágenes del campo: la interpretación antropológica del México rural, El Colegio de México, México.

Jacinto Zavala, Agustín, 1995, "Los requisitos del mando: valores tradicionales y retos actuales en la etnia p'urépecha de Michoacán”, en Relaciones, estudios de historia y sociedad, Año XVI, núm. 63-64, verano-otoño, pp. 11-27. 
Korsbaek, Leif, 1996, Introducción al sistema de cargos (antología), Universidad Autónoma del Estado de México, México.

Mauss, Marcel, 1979, Sociología y Antropología, Editorial Tecnos, España.

Medina, Andrés, 1995, "El sistema de cargos en la Cuenca de México: una primera aproximación a su trasfondo histórico", en Alteridades, Año 5, núm. 9, pp. 7-23.

Ochiai, Kazuyasu, 1985, Cuando los santos vienen marchando. Rituales públicos intercomunitarios tzotziles, Universidad Autónoma de Chiapas, San Cristóbal de las Casas, Chiapas.

Ortega Olivares, Mario y Fabiola Mora Rosales, 2014, “Mayordomías y fiestas patronales en los pueblos originarios de Santa Ana Tlacotenco y Santiago Tzapotitlan, Nahuas del Distrito Federal, México", Diálogo Andino. Revista de historia, geografía y cultura andina, 2014, junio, [en línea] disponible en http//:scielo.conicyt.cl/scielo.php?script=sci_arttext\&p id=50719-26812014000100005 [fecha de consulta: 16 de enero de 2018].

Ortiz, Daniel, 2017, “Aprueban 21 mil pesos para festividad de Cañada de Juanica”, en periódico Noreste de Guanajuato, 2017, 15 de agosto, [en línea] disponible en https://www.elnoreste. com [fecha de consulta: 23 de septiembre de 2017].

Padilla, Mario, 2000, Ciclo festivo y orden ceremonial: el sistema de cargos religiosos en San Pedro Ocumicho, El Colegio de Michoacán, México.

Piña Perusquía, Abel, 2002, La peregrinación otomí al Zamorano, Universidad Autónoma de Querétaro, México.

Rivera Farfán, Carolina, María del Carmen García Aguilar, Miguel Lisbona Guillén, Irene Sánchez Franco y Salvador Meza Días, 2005, Diversidad religiosa y conflicto en Chiapas. Intereses utopias y realidades, UNAM, CIESAS, COCyTECH, Secretaría de Gobierno del Estado de Chiapas, Secretaría de Gobernación, México.

Rodríguez, María Teresa, 1995, "Sistema de cargos y cambio religioso en la Sierra de Zongolica, Veracruz", en Alteridades, Año 5, núm. 9, pp. 63-69. 
Rubio, Jonathan, 2014, "Reactivarán a cuatro comunidades indígenas en Tierra Blanca", en periódico Correo, 2014, 19 de febrero, [en línea] disponible en https://www.correo.com [fecha de consulta: 6 de marzo de 2015].

Rus, Jan, 2002 [1995], "La comunidad revolucionaria institucional: la subversión del gobierno indígena en los Altos de Chiapas, 1936-1968", en Juan Pedro Viqueira y Mario Humberto Ruz (editores), Chiapas los rumbos de otra historia, UNAM, CIESAS, México, pp. 251-277.

Simons, Anna, 2000, "Gobierno", en Diccionario de antropología, Thomas Barfield (editor), Siglo XXI, México, pp. 265-266.

Urbina Villagómez, Mirtha Leonela, 2016, Urdir comunidad en tierra yerma. Reconstitución/Desestructuración en la Congregación otomi de San Ildefonso de Cieneguilla, Tierra Blanca, Guanajuato, Tesis de doctorado en Ciencias Sociales, El Colegio de San Luis A. C., México.

Uzeta, Jorge, 2004, El camino de los santos. Historia y lógica cultural otomi en la sierra gorda guanajuatense, El Colegio de Michoacán, Ediciones La Rana, México.

Uzeta, Jorge, 2010, "La relevancia política de documentos tardíos. Propiedades privadas en una congregación indígena”, en Andrew Roth Seneff (editor), Caras y Máscaras del México étnico. La participación indigena en las formaciones del Estado mexicano, Volumen I, El Colegio de Michoacán, México, pp. 95-110.

Wasserstrom, Robert, 1992 [1983], Clase y sociedad en el centro de Chiapas, FCE, México. 